\title{
Assessment of incidence of post-operative wound infection in women undergoing caesarean section: a retrospective study
}

\author{
Radha Sangavi*, Rajkumari K. S.
}

Department of Obstetrics and Gynecology, Raichur Institute of Medical Sciences, Raichur, Karnataka, India

Received: 27 March 2018

Accepted: 01 May 2018

*Correspondence:

Dr. Radha Sangavi,

E-mail: radhasangavi17@gmail.com

Copyright: (C) the author(s), publisher and licensee Medip Academy. This is an open-access article distributed under the terms of the Creative Commons Attribution Non-Commercial License, which permits unrestricted non-commercial use, distribution, and reproduction in any medium, provided the original work is properly cited.

\section{ABSTRACT}

Background: The surgical site infection is the second most common infectious complication occurring after caesarean section. Infections occurring after caesarean section represent a considerable burden to the healthcare systems and preventing these complications is a priority of healthcare systems especially in developing countries. The aim of this study was to determine the incidence of SSI in patients undergoing a LSCS at a RIMS teaching hospital, Raichur, and to identify risk factors, common bacterial pathogens and antibiotic sensitivity.

Methods: The present retrospective study was conducted in RIMS Institute, during a period of 3 years i.e. from $2013-$ 2016. In this study a total of 50 cases were collected from MRD department. They were divided into two groupscases and controls, each having 50 subjects each. Wound infection was defined as inflammation or sepsis with or without positive bacterial cultures. With SSI, there may be fever, redness, swelling and/or pain in the area around the incision site. Complete information regarding demographic data, the type and indication for caesarean section, duration of labour, duration of surgery and rupture of membrane were recorded. Wound infections occuring after 30 days of LSCS \& other gynaecological surgeries were excluded. All the results were analyzed by SPSS software 16.0. Chi-square test and student $t$ test were used for the assessment of level of significance. Probability value of less than 0.05 was considered significant.

Results: A total of 100 subjects were included in the present study, out of which, 50 were cases and the remaining 50 were controls. The mean age of the subjects was 37.45 years. There were 7 cases and 13 controls who were aged between 20-24 years. There was no significant difference amongst cases and controls regarding age. There was a significant difference in the haemoglobin levels amongst cases and controls. The third criterion that was assessed was duration of labour. Majority of the cases had prolonged labour whereas in majority of the controls, the duration of labour of labour was less than 6 hours. There was a significant difference in duration of labour amongst cases and controls $(\mathrm{p}<0.05)$. Elective $\mathrm{c}$ section was done in 2 cases and 6 controls. $\mathrm{C}$ section was performed in an emergency in 48 cases and 44 controls. There was a significant difference in the operation time between cases and controls $(\mathrm{p}<0.05)$. E.coli infection occurred in 15 cases in the present study followed by Actinobacter species which occurred in 13 cases. Absence of growth was seen in 5 cases.

Conclusions: The risk factors associated with SSI in our study were, haemoglobin levels, prolonged labour, duration of operation. The most common organisms isolated were E. coli and Actinobacter species.

Keywords: Haemoglobin, LSCS, Prolonged labour, Retrospective, SSI

\section{INTRODUCTION}

The incidence of caesarean section had increased widely in the past three decades. ${ }^{1}$ In the years 2010 , in the USA, caesarean section was the most commonly performed surgery and in 13 years its incidence has increased by $41 \% .^{2}$ Caesarean section is categorised as a clean contaminated wound. ${ }^{3}$ 
The surgical site infection is the second most common infectious complication occurring after caesarean section. Infections occurring after caesarean section represents a considerable burden to the healthcare systems and preventing these complications is a priority of healthcare systems especially in developing countries. ${ }^{4}$ The incidence of surgical site infection globally ranges between $0.5-15 \% .^{5}$ The basic definition of surgical site infection is any infection that targets surgical wound in uterus whenever it is manipulated. ${ }^{6,7}$ Various risk factors are involved in surgical site infection.

According to a review, obesity and chorioamnionitis are amongst the intrinsic maternal risk factors associated with surgical site infection. ${ }^{8}$ according to some, ethnicity is also a controversial risk factor for incisional surgical site infection. ${ }^{9,10}$ other risk factors such as obesity, diet and socioeconomic status are directly or indirectly related to ethinicity. ${ }^{11}$ According to a multivariable logistic regression by Assawapalanggool, ethnicity is a valid risk factor for incisional surgical site infection. ${ }^{12}$ Various other risk factors include improper antibiotic prophylaxis, labour chorioamnionitis, time period from rupture of membrane, emergency cases etc. ${ }^{13-16}$

Increased duration of surgery and low haemoglobin levels also acts as substantial risk factor for surgical site infection. ${ }^{14}$ Surgical site infection prolongs hospital stay, can require readmission, delays recovery, increases hospital costs and is associated with various morbidities.

Even in today's era, it continues to be a common postoperative infection in both developed and developing countries. Proper precautions need to be taken during and after surgery such that the incidence of SSI can be standardised. ${ }^{15}$ Therefore, the aim of this study was to determine the incidence of SSI in patients undergoing a LSCS at a regional referral hospital in RIMS, Raichur, and to identify risk factors, common bacterial pathogens $\&$ antibiotic sensitivity.

\section{METHODS}

The present retrospective study was conducted in RIMS Institute, during a period of 3 years i.e. from 2013-2016. In this study a total of 50 cases were collected from MRD department. They were divided into two groups- cases and controls, each having 50 subjects each.

The study was approved by the institute's ethical board. All those patients who had infections occurring within 30 days of the surgery which involved the skin, subcutaneous tissues and the fascia and muscle layers of the incision site were included in the study. The records of all the patients who delivered via CS were obtained from the MRD. The control group will consist of PCS cases which will be randomly selected during the same period, which would be routinely discharged on their third postoperative day without any symptoms of wound infections. Wound infections was defined as inflammation or sepsis with or without positive bacterial cultures. With SSI, there may be fever, redness, swelling and/or pain in the area around the incision site.

The Centres for Disease Control and Prevention (CDC) state that SSI should be suspected within 30 days of a surgical procedure if at least one of the following symptoms is present: localised swelling, with or without purulent discharge from the wound, pain or tenderness, redness, malodour or fever. The organisms isolated from the incision sites were investigated and antibiotic sensitivity was also measured.

Complete information regarding demographic data, the type and indication for caesarean section, duration of labour, duration of surgery and rupture of membrane were recorded. Amount of blood loss and details of postoperative hospital stay were also recorded. All the results were analyzed by SPSS software 16.0. Chi-square test and student $t$ test were used for the assessment of level of significance. Probability value of less than 0.05 was considered significant.

\section{RESULTS}

A total of 100 subjects were included in the present study, out of which, 50 were cases and the remaining 50 were controls. The mean age of the subjects was 37.45 years. There were 7 cases and 13 controls who were aged between 20-24 years as shown in Table 1.

There were 27 cases and 25 controls who were aged between 25-29 years. There were 9 cases and 8 controls who were aged between 30-35 years. There were 7 cases and 9 controls who were aged more than 35 years. There was no significant difference amongst cases and controls regarding age. There were 33 cases and 23 controls whose haemoglobin level was below $11 \mathrm{gm} / \mathrm{dl}$. There were 17 cases and 27 controls whose haemoglobin level was above $11 \mathrm{gm} / \mathrm{dl}$. The mean haemoglobin level amongst cases was $10.4 \pm 9.5 \mathrm{gm} / \mathrm{dl}$ and amongst controls were $9.7 \pm 3.6 \mathrm{gm} / \mathrm{dl}$. There was a significant difference in the haemoglobin levels amongst cases and controls. The third criterion that was assessed was duration of labour. Majority of the cases had prolonged labour whereas in majority of the controls, the duration of labour of labour was less than 6 hours as shown in Table 1.

There were 9 cases and 4 controls with duration of labour more than 12 hours. There was a significant difference in duration of labour amongst cases and controls $(\mathrm{p}<0.05)$. Elective $\mathrm{c}$ section was done in 2 cases and 6 controls. $\mathrm{C}$ section was performed in an emergency in 48 cases and 44 controls. There was a significant difference in type of surgery amongst cases and controls. The operation time was less than 60 minutes in 22 cases and 34 controls. The operation time was between 60-90 minutes amongst 18 cases and 11 controls. There was a significant difference in the operation time between cases and controls $(\mathrm{p}<0.05)$. 
Table 1: Socio demographic and clinical profile of the study.

\begin{tabular}{|c|c|c|c|c|}
\hline Characterstics & & Cases & Controls & $P$ value \\
\hline \multirow{4}{*}{ Age } & $20-24$ & 7 & 13 & \multirow{4}{*}{$>0.05$} \\
\hline & $25-29$ & 27 & 25 & \\
\hline & $30-35$ & 9 & 8 & \\
\hline & $>35$ & 7 & 9 & \\
\hline \multirow{3}{*}{ Haemoglobin } & $<11 \mathrm{gm} / \mathrm{dl}$ & 33 & 23 & \multirow{3}{*}{$<0.05$} \\
\hline & $>11 \mathrm{gm} / \mathrm{dl}$ & 17 & 27 & \\
\hline & Mean \pm SD & $10.4 \pm 9.5$ & $9.7 \pm 3.6$ & \\
\hline \multirow{4}{*}{ Duration of labour } & $<6$ hours & 8 & 25 & \multirow{4}{*}{$<0.05$} \\
\hline & 6-12 hours & 13 & 12 & \\
\hline & $>12$ hours & 9 & 4 & \\
\hline & No labour & 20 & 9 & \\
\hline \multirow{2}{*}{ Type of surgery } & Elective & 2 & 6 & \multirow{2}{*}{$<0.05$} \\
\hline & Emergency & 48 & 44 & \\
\hline \multirow{3}{*}{ Operation time } & $<60$ mins & 22 & 34 & \multirow{3}{*}{$<0.05$} \\
\hline & $60-90$ mins & 18 & 11 & \\
\hline & $>90$ mins & 10 & 5 & \\
\hline \multirow{2}{*}{ Interval of prophylactic antibiotic } & $<2$ hours & 11 & 28 & \multirow{2}{*}{$<0.05$} \\
\hline & $>2$ hours & 39 & 22 & \\
\hline
\end{tabular}

The interval between prophylactic antibiotic and surgery was less than 2 hours in 11 cases and 28 controls. The interval between prophylactic antibiotic and surgery was more than 2 hours in 39 cases and 22 controls. There was a significant difference in this interval between cases and controls $(\mathrm{p}<0.05)$. E. coli infection occurred in 15 cases in the present study followed by Actinobacter species which occurred in 13 cases. 15 cases in the present study which were found to be affected by E.coli were found to be sensitive for Pipercillin+Tozabactum, Imeprenem and Gentamycin. Staphylococcus aureus infection occurred in 12 cases. Absence of growth was seen in 5 cases as shown in Table 2.

Table 2: Culture and antibiotic sensitivity.

\begin{tabular}{|c|c|c|}
\hline $\begin{array}{l}\text { Number } \\
\text { cases }\end{array}$ & Organism & Antibiotic sensitivity \\
\hline 15 & E. coli & $\begin{array}{l}\text { Pipercillin+Tozabactum } \\
\text { Imeprenem, Gentamycin }\end{array}$ \\
\hline 13 & $\begin{array}{l}\text { Actinobacter } \\
\text { species }\end{array}$ & $\begin{array}{l}\text { Ampicillin+sulbactum } \\
\text { Meroprnum, } \\
\text { Tobramycin, } \\
\text { Levofloxacin }\end{array}$ \\
\hline 12 & $\begin{array}{l}\text { Staphylococcus } \\
\text { aureus }\end{array}$ & $\begin{array}{l}\text { Cefuroxime+sulbactum } \\
\text { Pipercillin+Tozabactum }\end{array}$ \\
\hline 5 & $\begin{array}{l}\text { Non-fermenting } \\
\text { Gr-ve bacilli }\end{array}$ & $\begin{array}{l}\text { Pipercillin+Tozabactum } \\
\text { Imeperenum }\end{array}$ \\
\hline 5 & No growth & - \\
\hline
\end{tabular}

\section{DISCUSSION}

The incidence of surgical site infection has ranged from $2.9 \%$ to $17.9 \% .^{18}$ It significantly alters the quality of life of patient by increasing morbidity and increasing the duration of hospital stays. A study conducted by Dhar et al to determine the incidence of surgical site infections (SSI) in patients undergoing a Caesarean section (CS) and to identify risk factors, common bacterial pathogens and antibiotic sensitivity. A retrospective study was conducted involving 50 controls and 50 cases of SSI. Wound infection was seen in considerable cases. The risk factors for postoperative wound infection were rupture of membrane, diabetes. In majority of the cases, the organism isolated was staphylococcus aureus followed by gram negative Escherichia coli as shown in Table 2. Majority of the organisms were sensitive to aminoglycoside and cephalosporin. Polymicrobial infections were seen in few cases, while in 5 cases yielded no growth. ${ }^{19}$

In a separate studies conducted by Donowitz et al and Beattie et al emergency $\mathrm{C}$ section is associated with significantly higher incidence of postoperative wound infection. ${ }^{20,21}$ In our study also, C section was performed in an emergency in $97 \%(n=194)$ cases and $88 \%(n=176)$ controls. There was a significant difference in type of surgery amongst cases and controls. A study conducted by Kasatpibal et al to the incidence of SSI in 9 hospitals, with patterns of surgical antibiotic prophylaxis, risk factors and common causative pathogens involved in SSI.

Antibiotic prophylaxis was categorized into preoperative, intraoperative, and postoperative. Risk factors for SSI were determined using multiple logistic regression models. The study included 8764 patients with 8854 major operations. The SSI rate was 1.4 infections/100 operations. The 3 most common operative procedures 
that lead to surgical site infection were were cesarean section, appendectomy, and hysterectomy. Escherichia coli, Staphylococcus aureus, and Pseudomonas aeruginosa were the most commonly isolated microorganisms. Ampicillin/amoxicillin, cefazolin, and gentamicin were commonly used for antibiotic prophylaxis as shown in Table 1. The risk factors for surgical site infection in their study were high degree of wound contamination, prolonged hospital stay, emergency operation, and prolonged duration of operation. ${ }^{22}$ In our study also, the operation time was less than 60 minutes in 22 cases and 34 controls.

The operation time was between 60-90 minutes amongst 18 cases and 11 controls. There was a significant difference in the operation time between cases and controls $(\mathrm{p}<0.05)$. The interval between prophylactic antibiotic and surgery was less than 2 hours in 11 cases and 28 controls. The interval between prophylactic antibiotic and surgery was more than 2 hours in 39 cases and 22 controls. There was a significant difference in this interval between cases and controls $(p<0.05)$. In a study conducted by Dahiya et al, there were $66.7 \%$ anemic patients who had surgical site infection postoperatively. ${ }^{23}$ They concluded that haemoglobin levels are a significant risk factor in SSI. In our study, there were 33 cases and 23 controls whose haemoglobin level was below 11 $\mathrm{gm} / \mathrm{dl}$. There were 17 cases and 27 controls whose haemoglobin level was above $11 \mathrm{gm} / \mathrm{dl}$. The mean haemoglobin level amongst cases was $10.4 \pm 9.5 \mathrm{gm} / \mathrm{dl}$ and amongst controls were $9.7 \pm 3.6 \mathrm{gm} / \mathrm{dl}$. There was a significant difference in the haemoglobin levels amongst cases and controls. Various measures need to be taken to reduce the incidence of SSI, these include proper infection control protocol and administration of proper postoperative and intraoperative antibiotic prophylaxis.

\section{CONCLUSION}

Assessment of risk factors should be done before surgery to determine the incidence and risk of SSI. Modification of these risk factors can reduce the chances of SSI. Discipline of the operation theatre should be strictly followed. The risk factors associated with SSI in our study were, haemoglobin levels, duration of operation \& prolonged labour.

Funding: No funding sources Conflict of interest: None declared

Ethical approval: The study was approved by the Institutional Ethics Committee

\section{REFERENCES}

1. Betran AP, Merialdi M, Lauer JA, Bing-Shun W, Thomas J, Van Look P, et al. Rates of caesarean section: analysis of global, regional and national estimates. Paediatr Perinat Epidemiol. 2007;21:98113.
2. Pfuntner A, Wier LM, Stocks C. Most Frequent Procedures Performed in U.S. Hospitals, 2010. HCUP Statistical Brief \#149. 2013.

3. Bruce J, Russel EM, Mollison J. the measurement and monitoring of surgical adverse events. Health Technol Assessment. 2001;5:13-28.

4. Nwankwo EO, Ibeh I, Enabulele OI. Incidence and risk factors of surgical site infection in a tertiary health institution in Kano, northwestern Nigeria. Int J Infect Control. 2012;8:1-6.

5. Arabashahi KS, Koohpayezade J. Investigation of risk factors for surgical wound infection among teaching hospital in Tehran. Int Wound J. 2006;3:5962.

6. Horan TC, Gaynes RP, Martone WJ, Jarvis WR, Emori TG. CDC definitions of nosocomial surgical site infections, 1992: a modification of CDC definitions of surgical wound infections. Infect Control Hosp Epidemiol. 1992;13:606-8.

7. Garner JS, Jarvis WR, Emori TG, Horan TC, Hughes JM. CDC definitions for nosocomial infections, 1988. Am J Infect Control. 1988;16:128-40.

8. Lakhan P, Doherty J, Jones M, Clements A. A systematic review of maternal intrinsic risk factors associated with surgical site infection following caesarean sections. Healthc Infect. 2010;15:35-41.

9. Beattie PG, Rings TR, Hunter MF, Lake Y. Risk factors for wound infection following caesarean section. Aust N Z J Obstet Gynaecol. 1994;34:398402.

10. Noyes N, Berkeley AS, Freedman K, Ledger W. Incidence of postpartum endomyometritis following single-dose antibiotic prophylaxis with either ampicillin/sulbactam, cefazolin, or cefotetan in highrisk caesarean section patients. Infect Dis Obstet Gynecol. 1998;6:220-3.

11. Olsen MA, Butler AM, Willers DM, Devkota P, Gross GA, Fraser VJ. Risk factors for endometritis after low transverse caesarean delivery. Infect Control Hosp Epidemiol. 2010;31:69-77.

12. Assawapalanggool S, Kasatpibal N, Sirichotiyakul S, et al. Risk factors for caesarean surgical site infections at a Thai-Myanmar border hospital. Am J Infect Control. 2016;44:990-5.

13. Farret TCF, Dallé J, da Silva Monteiro V, Arora R, Suntornlimsiri W. Risk factors for surgical site infection following caesarean section in a Brazilian Women's Hospital: a case-control study. Braz J Infect Dis. 2015;19:113-7.

14. Gong SP, Guo HX, Zhou HZ, Chen L, Yu YH. Morbidity and risk factors for surgical site infection following caesarean section in Guangdong Province, China. J Obstet Gynaecol Res. 2012;38:509-15.

15. Killian CA, Graffunder EM, Vinciguerra TJ, Venezia RA. Risk factors for surgical-site infections following caesarean section. Infect Control Hosp Epidemiol. 2001;22:613-7.

16. Shree R, Park SY, Beigi RH, Dunn SL, Krans EE. Surgical site infection following cesarean delivery: 
patient, provider, and procedure-specific risk factors. Am J Perinatol. 2016;33:157-64.

17. Gould D. Caesarean section, surgical site infection and wound management. Nurs Stand. 2007;21:57-62.

18. Ward VP, Charlett A, Fagan J, Crawshaw SC. Enhanced surgical site infection surveillance following caesarean section: Experience of a multicenter collaborative post-discharge system. J Hosp Infect. 2008;70:166-73.

19. Dhar H, Al-Busaidi I, Rathi B, Nimre EA, Sachdeva V, Hamdi I. A Study of Post-Caesarean Section Wound Infections in a Regional Referral Hospital, Oman. Sultan Qaboos University Medical J. 2014;14(2):211-7.

20. Donowitz LG, Wenzel RP. Endometritis following caesarean section. A controlled study of the increased duration of hospital stay and direct cost of hospitalization. Am J Obstet Gynecol. 1980;137:4679.
21. Beattie PG, Rings TR, Hunter MF, Lake Y. Risk factors for wound infection following caesarean section. Aust N Z J Obstet Gynaecol. 1994;34:398402.

22. Kasatpibal N, Jamulitrat S, Chongsuvivatwong V. Standardized incidence rates of surgical site infection: a multicenter study in Thailand. Am J Infect Control. 2005;33(10):587-94.

23. Dahiya P, Gupta V, Pundir S, Chawla D. Study of incidence and risk factors for surgi-acal site infection after cesarean section at first referral unit. Interna $\neg$ tional $\mathrm{J}$ Contemporary Med Res. 2016;3(4):1102-4.

Cite this article as: Agrawal S, Das V, Agarwal A, Pandey A. Fetal Doppler for prediction of adverse perinatal outcome in preeclampsia in a low resource setting. Int J Reprod Contracept Obstet Gynecol 2018;7:2328-32. 